\title{
Measuring the polymerization stress of self-adhesive resin composite cements by crack propagation
}

\author{
Felicitas Wiedenmann $^{1}$ (D) $\cdot$ Fabian Becker ${ }^{1} \cdot$ Marlis Eichberger $^{1} \cdot$ Bogna Stawarczyk $^{1}$
}

Received: 30 January 2020 / Accepted: 3 June 2020 / Published online: 15 June 2020

(C) The Author(s) 2020

\begin{abstract}
Objectives To test the polymerization stress of nine self-adhesive resin composite cements (G-CEM, iCEM, Bifix SE, Maxcem Elite, PANAVIA SA, SoloCem, SmartCem 2, SpeedCEM, RelyX Unicem 2) and one glass ionomer cement (control group; Ketac Cem).

Materials and methods The crack propagation of a feldspar ceramic $(n=130)$ was determined by measuring crack lengths that originated from Vickers indentations, prior to and after the application and polymerization of the self-adhesive resin cements. Results for crack propagation were converted to polymerization stress values, and statistical analysis was performed using oneway ANOVA followed by Scheffé post hoc test.

Results SmartCem 2 presented higher stress values than iCEM, SoloCem, and Ketac Cem, while Ketac Cem showed lower values than Bifix SE, Maxcem Elite, SmartCem 2, SpeedCEM, and RelyX Unicem 2.

Conclusions Self-adhesive resin composite cements differ in their polymerization stress, which may affect the durability of the restoration. For restorations made from ceramics with lower flexural strength, such as feldspar ceramics, resin composite cement materials with less polymerization stress should be preferred.

Clinical Relevance As a high polymerization shrinkage may increase crack propagation, the determination of the polymerization stress of self-adhesive resin composite cements employed for fixing all-ceramic restorations is an important factor.
\end{abstract}

Keywords Crack propagation · Vickers indentation $\cdot$ Polymerization stress $\cdot$ Self-adhesive resin composite cement $\cdot$ Feldspar ceramic

\section{Introduction}

The fixation of all-ceramic restorations with resin composite cements allows for optimal esthetic results, while the powerful bond to the natural tooth can protect and preserve dental hard tissue, as retentive preparations become unnecessary [1]. The adhesive bond can furthermore stabilize brittle ceramic restorations, resulting in a greater resistance to external forces [2]. In addition, resin composite cements can compensate small inaccuracies of the restauration [3].

Most systems are, however, prone to error due to elaborate fastening processes, calling for a prior conditioning and

Felicitas Wiedenmann

felicitas.wiedenmann@med.uni-muenchen.de

1 Department of Prosthetic Dentistry, University Hospital of Munich (LMU), Goethestraße 70, 80336 Munich, Germany pretreatment with an adhesive system. In this context, selfadhesive resin composite cements can constitute an alternative by achieving an adhesive bond between restoration and tooth without a preceding treatment of the natural tooth $[4,5]$. Expect for several investigations examining different selfadhesive resin composite cements in regard to their potentially successful bonding to teeth [6-8]; few studies exist that investigate the wider implications of employing these materials.

During polymerization, the mixing of the monomeric compounds allows for the formation of a polymer by the continuous addition of active chain ends. The volume of the material subsequently decreases, as carbon double bonds are converted to carbon single bonds $[9,10]$. These transitions result in polymerization stress, as polymerization shrinkage is hindered by the adjoining tooth surface and the resin itself. Polymerization stress is highly dependent on the gel point of the polymer, as within certain limits, shrinkage can be compensated due to a continued flow of the composite before reaching the gel point $[11,12]$. In the post-gel phase, the 
polymer does, however, change its properties from a highly viscous liquid to a solid elastic phase [13], in which shrinkage cannot be compensated. Polymerization stress is thus generated within the resin composite cement, the tooth, and the adjoining surface $[14,15]$. This phenomenon is affected by the composition of the material $[16,17]$ and the polymerization process itself [9]. In a clinical setting, polymerization stress can cause the formation of gaps and an ensuing discoloration of the restoration, the development of caries, fatigue fractures, or even a total failure of the restoration [18-21].

Over the course of time, different methods have been developed to determine the polymerization stress of resin composites, from the modified dilatometer employing a mercury column [22], and the deflecting disc technique measuring the deflection of a $0.13-\mathrm{mm}$-thin glass plate [23] to elaborate methods such as micro-computed tomography [24]. Nonetheless, each method holds different disadvantages, such as a high sensitivity to temperature variations [22] or a large variability of the results due to the fragile study setup [23]. One relatively simple yet conclusive method to measure polymerization stress is the calculation through crack propagation in brittle materials [15]. The aim of this study was to determine the polymerization stress of self-adhesive resin composite cements using Vickers indentations and crack propagation in a feldspar ceramic. The study tested the null hypothesis that self-adhesive resin composite cements do not differ in their development of polymerization stress. One glass ionomer cement was included in the study design to act as a control group.

\section{Materials and methods}

The crack propagation of a feldspar ceramic (VITABLOCS Mark II, VITA Zahnfabrik, Bad Säckingen, Germany; Table 1) was determined by measuring crack lengths that originated from Vickers indentations, prior to and after the application and subsequent polymerization of nine different self-adhesive resin composite cements and one glass ionomer cement (control group; Fig. 1, Table 2).

Table 1 Physical data for the feldspar ceramic VITABLOCS Mark II

\begin{tabular}{ll}
\hline Property & Values \\
\hline Thermal expansion coefficient $\left(25-500{ }^{\circ} \mathrm{C}\right)$ & $9.4 \pm 0.1 * 10^{-6} \cdot \mathrm{K}^{-1}$ \\
Density & $2.44 \pm 0.01 \mathrm{~g} / \mathrm{cm}^{3}$ \\
Flexural strength (Schwickerath) (ISO 6872) & $154 \pm 15 \mathrm{MPa}$ \\
E-Modul (resonance method) & $45 \pm 0.5 \mathrm{GPa}$ \\
Transformation range & $780-790^{\circ} \mathrm{C}$ \\
\hline
\end{tabular}

Source: VITA Zahnfabrik, Bad Säckingen, Germany

\section{Specimen preparation}

VITABLOCS Mark II were sliced under water cooling into 2.35-mm-thick discs using a diamond saw (Secotom 50, Struers, Ballerup, Denmark; $N=260$ ). For respectively half the discs (hereafter referred to as top disc), a cylindrical hole with a diameter of $2.5 \mathrm{~mm}$ was manually drilled into the middle of each top disc using a turbine (K-Air Plus, KaVo, Biberbach/Riß, Germany) equipped with a diamond drill (S6856, Gebr. Brasseler, Lemgo, Germany; Fig. 2) under water cooling. The top and bottom of each disc were then polished in five steps to $4 \mu \mathrm{m}$ under water cooling with a polishing machine (Abramin, Struers) to produce discs with a final dimension of $12 \times 14 \times 2 \mathrm{~mm}$. Discs were annealed at $680^{\circ} \mathrm{C}$ for $10 \mathrm{~h}$ (Arca20, Schütz Dental, Rosbach, Germany) to release possible residual stress from the processing procedure. Prior to bonding, discs were carefully cleaned with ethanol (96\%, Otto Fischar). Top discs (possessing the drilled hole) and bottom discs (whole discs) were then bonded to each other employing a silicone template ensuring an exact positioning with cyanoacrylate to produce a total of 130 specimens.

\section{Measurement of the crack propagation}

To initiate crack formation in the ceramics, four Vickers indentations per specimen were performed using a load of $58.8 \mathrm{~N}$ for $15 \mathrm{~s}$ with a universal hardness testing machine (ZHU0.2/Z2.5, Zwick/Roell, Ulm, Germany; Fig. 3). The Vickers indenter was oriented to allow for a parallel alignment of the two radial cracks with the cavity edge, with each indentation centered at a distance of $570 \mu \mathrm{m}$ from the edge of the hole (Fig. 2) [15]. The ceramic was subsequently set aside and dried in a desiccator (Duran Exsikkator, Duran Group, Mainz, Germany) at $23{ }^{\circ} \mathrm{C}$ for $24 \mathrm{~h}$ to allow for a slow crack growth induced by residual stress [4]. The length of the two cracks originating from each Vickers indentation was determined at a magnification of $\times 200$ using the software of the universal hardness testing machine (TestXpert II, Version 3.2, Zwick/ Roell; Fig. 4), and an average length (c) was calculated for each specimen.

\section{Application of the different cements and subsequent polymerization}

To protect the Vickers indentations from contamination, they were covered with Mylar tape. The ceramic surface was pretreated with hydrofluoric acid (Ultradent Porcelain Etch, Ultradent Products, Inc., St. Louis, USA) and silane coupling agents (CLEARFIL CERAMIC PRIMER, Kuraray, Tokyo, Japan, or Monobond Plus, Ivoclar Vivadent, Schaan, Liechtenstein) strictly following the manufacturers' recommendation (Fig. 1). The holes were then filled with increments 


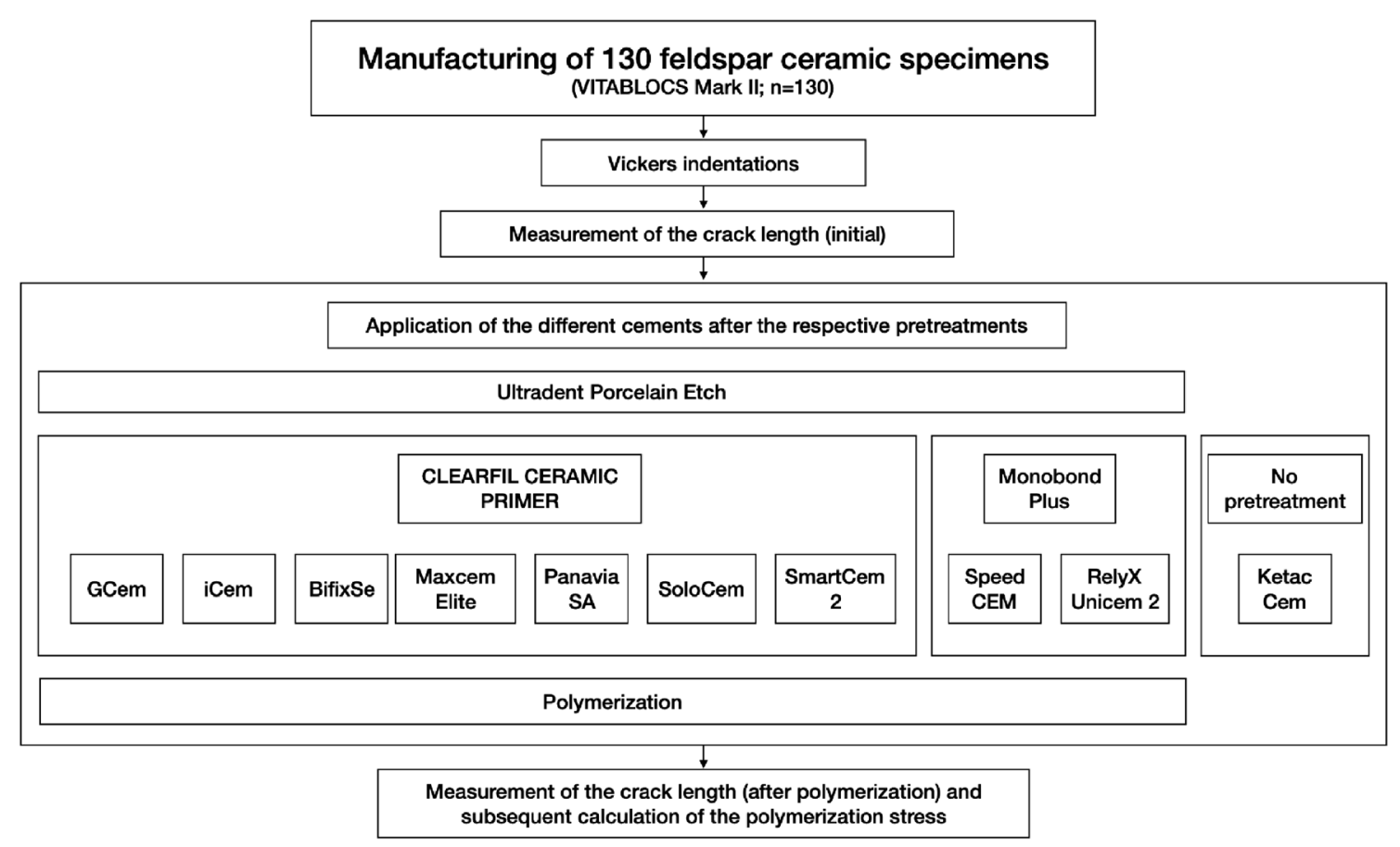

Fig. 1 Study design

of the nine self-adhesive resin composite cements ((1) GCEM, GC Europe, Leuven, Belgium; (2) iCEM, Kulzer, Hanau, Germany; (3) Bifix SE, VOCO, Cuxhaven, Germany; (4) Maxcem Elite, Kerr, Orange, USA; (5) PANAVIA SA, Kuraray; (6) SoloCem, Coltene/Whaledent, Altstätten, Switzerland; (7) SmartCem 2, Dentsply Sirona, Konstanz, Germany; (8) SpeedCEM, Ivoclar Vivadent; (9) RelyX Unicem 2, 3M, Seefeld, Germany) or the glass ionomer cement (control group; Ketac Cem, 3M, Seefeld, Germany; $n=13$ per subgroup). Specimens were covered with Mylar tape before curing of the self-adhesive resin composite cements was performed using a LED polymerization device with wavelengths between 430 and $480 \mathrm{~nm}$ (Elipar $\mathrm{S} 10,3 \mathrm{M}$ ) for $60 \mathrm{~s}$. The glass ionomer cement was self-cured. After polymerization, specimens were stored for $10 \mathrm{~min}$ before a repeated measurement of the crack length was performed.

\section{Determination of the polymerization stress}

To calculate the polymerization stress, the equation by Yamamoto et al.:

$\sigma=\frac{\left[K c-\Phi / c^{\prime 3 / 2}\right]}{Y c^{\prime 1 / 2}}$

was used [15], where $\sigma$ is the polymerization stress of the ceramic, $K_{\mathrm{c}}$ is the fracture toughness $\left(1.37 \mathrm{MPa} \mathrm{m}^{1 / 2}\right), \Phi=$ $\mathrm{K}_{\mathrm{c}} \mathrm{c}^{3 / 2}, c$ is the initial crack length, $c^{\prime}$ is the crack length after polymerization, and $Y$ is the geometrical term equal to 1.12 $\pi^{1 / 2}$.

\section{Statistical analysis}

Descriptive analysis followed by Kolmogorov-Smirnov and Shapiro-Wilk test for testing the violation of normal distribution was calculated. Data were analyzed using one-way ANOVA followed by Scheffé post hoc test. All $p$ values below 0.05 were construed as statistically significant. Data were analyzed with SPSS version 25.0 (IBM, Armonk, NY, USA).

\section{Results}

Initial crack lengths ranged from $209.4 \pm 9.9$ to $222.6 \pm$ $11.1 \mu \mathrm{m}$ (Table 3). After polymerization, the shortest crack length of $223.6 \pm 11.5 \mu \mathrm{m}$ was measured within the control group, while the application of RelyX Unicem 2 led to the longest crack length of $236.6 \pm 9.5 \mu \mathrm{m}$. In line with these absolute values, the control group presented a significantly lower crack growth of only $1.0 \pm 5.2 \mu \mathrm{m}$, while the application of RelyX Unicem 2 led to the highest crack growth (18.9 \pm $7.3 ; p=0.05$ ). Crack propagation is displayed in Fig. 4 for one specimen initial (a) and after polymerization (b) of the selfadhesive resin composite cement RelyX Unicem $2(\times 200$ magnification). The crack growth after polymerization is clearly visible on the left side of $\mathbf{b}$; the black arrow indicates a chipping of the ceramic next to the Vickers indentation after polymerization.

SmartCem 2 presented higher stress values than iCEM, SoloCem, and Ketac Cem $(p<0.001-0.042)$, while Ketac Cem showed lower values than Bifix SE, Maxcem Elite, 
Table 2 Materials, manufacturers, compositions, and Lot No. used

\begin{tabular}{|c|c|c|c|}
\hline Material & Manufacturer & Composition & Lot No. \\
\hline $\begin{array}{l}\text { VITABLOCS Mark } \\
\text { II }\end{array}$ & $\begin{array}{l}\text { VITA Zahnfabrik, Bad } \\
\text { Säckingen, Germany }\end{array}$ & $\mathrm{SiO}_{2}: 56-64, \mathrm{Al}_{2} \mathrm{O}_{3}: 20-23, \mathrm{Na}_{2} \mathrm{O}: 6-9, \mathrm{~K}_{2} \mathrm{O}: 6-8, \mathrm{CaO}: 0.3-0.6, \mathrm{TiO}_{2}: 0.0-0.1$ & 7453 \\
\hline $\begin{array}{l}\text { Ultradent Porcelain } \\
\text { Etch }\end{array}$ & $\begin{array}{l}\text { Ultradent Products, Inc., } \\
\text { St. Louis, USA }\end{array}$ & Buffered $9 \%$ hydrofluoric acid & B863L \\
\hline $\begin{array}{l}\text { CLEARFIL } \\
\text { CERAMIC } \\
\text { PRIMER }\end{array}$ & Kuraray, Tokyo, Japan & $\begin{array}{l}\text { 3-Methacryloxypropyl trimethoxy silane, 10-methacryloyloxydecyl dihydrogen } \\
\text { phosphate, ethanol }\end{array}$ & 57002 \\
\hline Monobond Plus & $\begin{array}{l}\text { Ivoclar Vivadent, Schaan, } \\
\text { Liechtenstein }\end{array}$ & Ethanol, silane, methacrylate phosphoric ester & P20536 \\
\hline G-CEM & $\begin{array}{l}\text { GC Europe, Leuven, } \\
\text { Belgium }\end{array}$ & $\begin{array}{l}\text { Urethane dimethacrylate (UDMA), dimethacrylate (DM), 4-MET, fluoroaluminosilicate } \\
\text { glass, pigments, silica, initiators, stabilizers, camphorquinone, hydroperoxides }\end{array}$ & 1309191 \\
\hline iCEM & Kulzer, Hanau, Germany & Di-, tri-, und multifunctional acrylates, initiators, stabilizers & 405009 \\
\hline Bifix SE & $\begin{array}{l}\text { VOCO, Cuxhaven, } \\
\text { Germany }\end{array}$ & $\begin{array}{l}\text { UDMA, bis-GMA, gly-DMA, phosphate-based monomers, initiators, stabilizers, glass } \\
\text { filler, catalysts }\end{array}$ & 7435 \\
\hline Maxcem Elite & Kerr, Orange, USA & $\begin{array}{l}\text { Hydroxyethylmethacrylate (HEMA), 4-methoxyphenol (MEHQ), cumolhydroperoxid } \\
\text { (CHPO), uncured methacrylate monomers, titanium dioxide }\left(\mathrm{TiO}_{2}\right) \text { and pigments, } \\
\text { barium-alumina silica glass, fluoroalumina silicate glass, nano-ytterbium fluoride }\end{array}$ & 4960205 \\
\hline PANAVIA SA & $\begin{array}{l}\text { Kuraray, } \\
\text { Tokyo, Japan }\end{array}$ & $\begin{array}{l}\text { Bisphenol-A-diglycidylmethacrylate, sodium fluoride, triethyleneglycoldimethacrylate, } \\
\text { 10-methacryloyloxydecyl-dihydrogenphosphate, hydrophobic aromatic } \\
\text { dimethacrylate, hydrophobic aliphatic dimethacrylate, silanized barium glass filler, } \\
\text { silanized colloidal silica, dl-camphorquinone, initiators, accelerators, catalysts }\end{array}$ & 5 U0009 \\
\hline SoloCem & $\begin{array}{l}\text { Coltene/Whaledent, } \\
\text { Altstätten, Switzerland }\end{array}$ & $\begin{array}{l}\text { UDMA, TEGDMA, 4-META, 2-hydroxyethylmethacrylate, dibenzoylperoxide, } \\
\text { benzoylperoxide }\end{array}$ & F18973 \\
\hline SmartCem 2 & $\begin{array}{l}\text { Dentsply Sirona, } \\
\text { Konstanz, Germany }\end{array}$ & $\begin{array}{l}\text { Urethane dimethacrylate resin, ethoxylated bisphenol-A-dimethacrylate, } \\
\text { trimethylolpropane, trimethacrylate, } 2,2 \text { '-ethylendioxydiethyldimethacrylate, } \\
\text { dimethylbenzylhydroperoxide, fluoroalumina silicate glass, catalysts, stabilizers, } \\
\text { titanium dioxide, silicon }\end{array}$ & 130430 \\
\hline SpeedCEM & $\begin{array}{l}\text { Ivoclar Vivadent, Schaan, } \\
\text { Liechtenstein }\end{array}$ & $\begin{array}{l}\text { UDMA, triethyleneglycoldimethacrylate, polyethyleneglycoldimethacrylate, } \\
\text { methacrylate phosphoric acid ester, dibenzoylperoxide, initiators, catalysts, barium } \\
\text { glass, ytterbium, fluoride, silica }\end{array}$ & 515015 \\
\hline RelyX Unicem 2 & 3M, Seefeld, Germany & $\begin{array}{l}\text { Glass powder, mixture of mono-, di-, and tri-glycerol dimethacrylate esters of phosphoric } \\
\text { acid, 2,2'-ethylendioxydiethyldimethacrylate, silica treated with silane, } \\
\text { dinatriumperoxodisulfate, glass, oxides, chemicals }\end{array}$ & 512279 \\
\hline Ketac Cem & 3M, Seefeld, Germany & $\begin{array}{l}\text { Silane-treated fillers, water, 2-hydroxyethylmethacrylate, silica treated with silane, } \\
\text { 4-dimethylamino-phenethyl alcohol }\end{array}$ & 537468 \\
\hline
\end{tabular}

SmartCem 2, SpeedCEM, and RelyX Unicem $2(p<0.001-$ $0.004)$ (Table 4$)$. The remaining groups were in the same value range $(p>0.05)$.

\section{Discussion}

While one previous study observed self-adhesive resin composite cements to present lower stress values than conventional resin-based cements [6], information about the development of polymerization stress in these materials is very rare. Therefore, the aim of this study was to examine the polymerization stress of nine self-adhesive resin composite cements as well as one conventional glass ionomer cement (control group) using Vickers indentations and crack propagation in a feldspar ceramic.

As the tested self-adhesive resin composite cements differed in their development of polymerization stress, the null hypothesis had to be rejected. As the development of polymerization stress depends on the filler content of the different materials $[8,16]$, with an inverse relationship between filler content and polymerization shrinkage existing [17], a high proportion of inorganic components should result in lower polymerization stress values. Nonetheless, an increased filler content might also adversely affect the conversion rate, as reactive groups are hindered in their free movement, while a polymerization by light activation is impaired by an increased light scattering [17]. As one previous study could demonstrate, the matrix might furthermore hold a stronger influence on stress values than the inorganic content [17]. The varying expansion behavior of the different self-adhesive resin composites could represent an additional perspective, as it might contribute to the observed findings. The initial expansion, created by an exothermic reaction and the heat generated by the curing unit, is, however, quickly compensated by the ensuing contraction early on in the curing process. A larger initial expansion in the different materials could, however, result in lower shrinkage values [8]. One further aspect is 


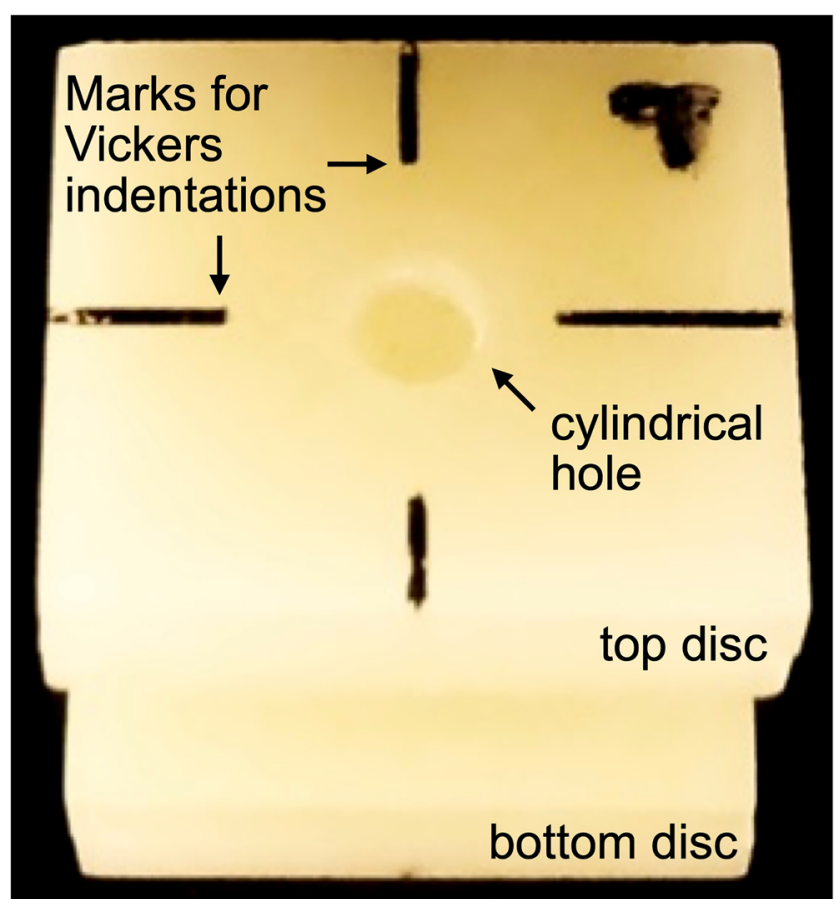

Fig. 2 A specimen depicted with the centrally located hole of $2.5 \mathrm{~mm}$ and marks indicating the position of the four Vickers indentations

constituted by the potential later hygroscopic expansion behavior of these materials when in situ $[25,26]$ that can induce and reinforce crack propagation of the ceramic restoration. Self-adhesive resin cements have been observed to exhibit high values of water expansion stress [26].

In the present study, SmartCem 2 showed higher polymerization stress values than the self-adhesive resin composite cements iCEM and SoloCem. This is in line with a previous investigation reporting the highest contraction stress for SmartCem 2 in comparison with six other self-adhesive resin composite cements [26]. To draw conclusions based on this resin composite's composition poses to be difficult, as the exact proportions of the various components are not supplied by the manufacturer. While an increase in polymerization stress can be traced back to a higher shrinkage during

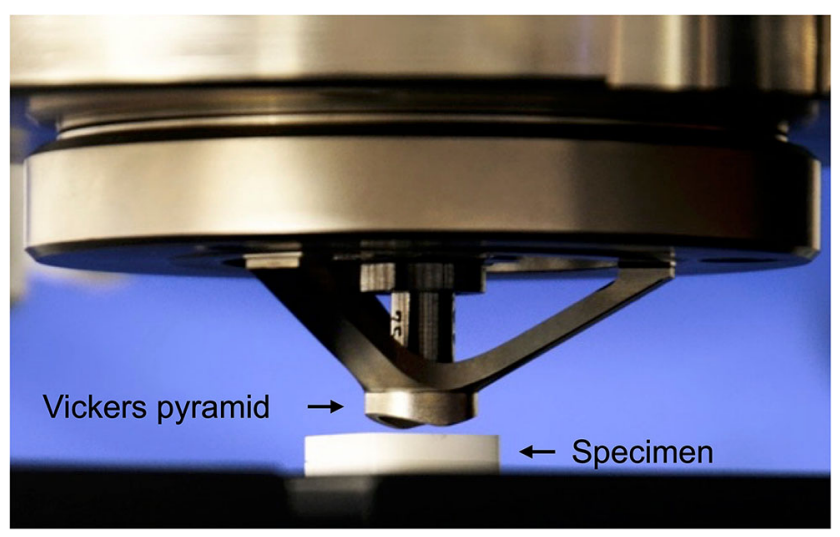

Fig. 3 Setup for performing the Vickers indentations polymerization, it might also indicate a strong bond between ceramic and mounting material, as the crack grows until the bond dissolves [15]. Previous studies investigating the shear bond strength of SmartCem 2 observed consistently high results $[27,28]$. To the authors' best knowledge, the polymerization stress of this particular resin composite cement has not been examined beforehand. Future studies should focus on examining the two self-adhesive resin composite cements iCEM and SoloCem further, as they presented low polymerization values while allowing a self-adhesive, and thus less error prone, fixation of dental restorations. Previous studies have observed iCEM to present comparable bond strength results between ceramic and dentin after water storage as a reference etch-and-rinse resin cement [29] and to show promising results in regard to the marginal adaptation and sealing of both enamel and dentin [30]. One study investigating the hygroscopic expansion of self-adhesive resin cements after water storage did, however, report a progressive crack propagation of VITABLOCS Mark II from deep initial cracks caused during CAD/CAM processing over time [25]. SoloCem has been observed to possess a high radiopacity [31] and a high water absorbance while nonetheless yielding low levels of discoloration [32]. As it has been demonstrated that a delay of 3-5 min prior to light activation of dual-cured resin composite cements can reduce shrinkage stress and improve bond strength without significantly altering mechanical properties, this parameter should be investigated in future studies examining resin composite cements [33].

The glass ionomer cement Ketac Cem presented lower polymerization stress values than most of the tested selfadhesive resin composite cements. While this drawback has to be taken into account when choosing either a self-adhesive or a conventional cement, Ketac Cem has been shown to lead to inferior results than various self-adhesive resin composite cements in regard to long-term stability [34, 35] and bond strength $[36,37]$. In the case of retentive preparations and high-strength ceramics such as monolithic zirconia, employing conventional glass ionomer cements can, however, entail many advantages [38]. As an adhesive is not required, a prolonged drainage becomes redundant. This can be especially helpful for deep posterior defects, where accessibility can be complicated. Compared with composite resins that enable the stabilization of the natural tooth structure through a strong composite-tooth bond [39], indications can, however, be limited (e.g., teeth presenting with large defects that are prone to fracture). Furthermore, glass ionomer cements are not recommended for restorative materials possessing a flexural strength lower than $350 \mathrm{MPa}$, as these restorations should be adhesively bonded to increase the overall stability and long-term outcome of the restoration [40].

As polymerization stress can lead to chipping (as depicted in Fig. 4) and the formation of marginal gaps, entailing dire 


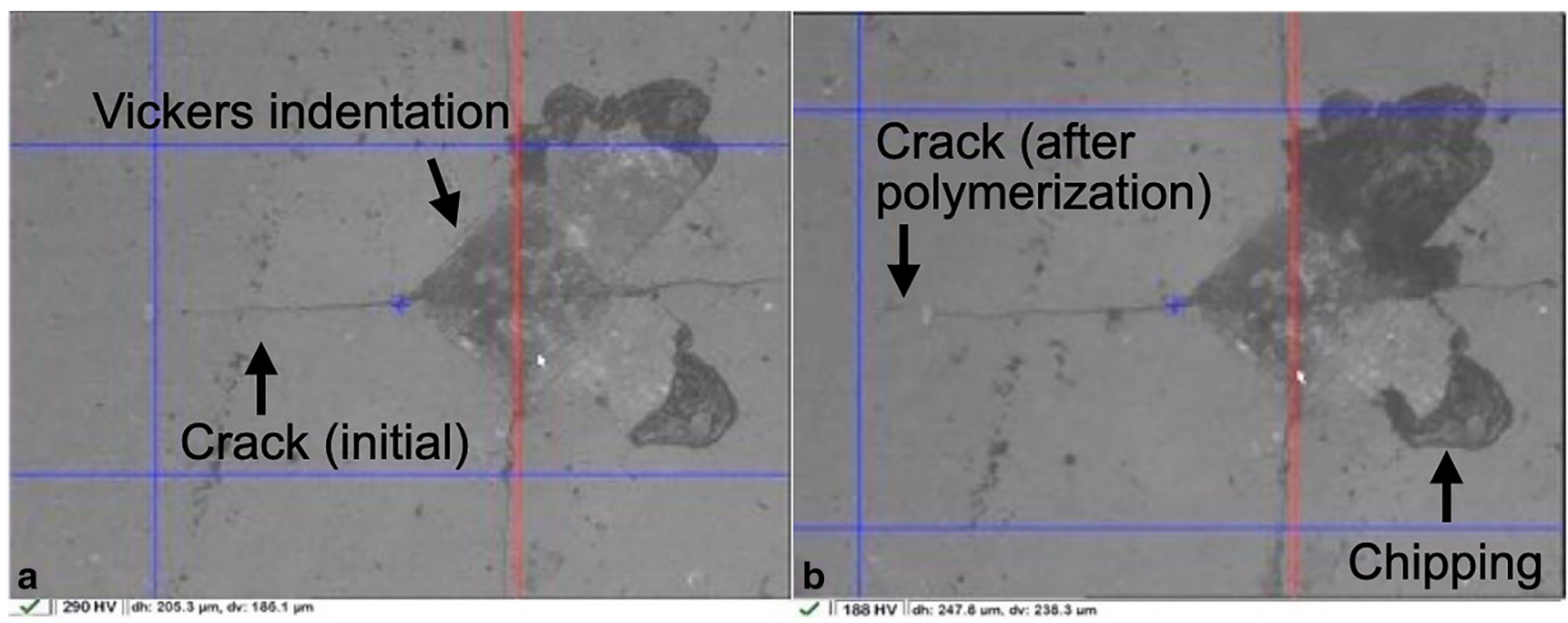

Fig. 4 Determination of the crack propagation (initial (a) and after polymerization (b) of the self-adhesive resin composite cement RelyX Unicem 2)

consequences such as discoloration, secondary caries, fatigue fractures, and postsurgical hypersensitivity up to the total failure of a restauration [12], it represents a crucial factor that should be considered when selecting a self-adhesive resin composite cement. Although a higher polymerization stress entails many negative consequences, it might also indicate a strong bond between ceramic and mounting material, as the crack grows until the bond dissolves [15]. Further studies are warranted to investigate a possible correlation between bond strength and crack propagation. The measured stress values of the present study cannot be directly transferred to the clinical situation, as additional factors present in the oral cavity must be taken into account. An increase in ambient temperature could, for example, lead to greater shrinkage [14]. In addition, curing can differ in the clinical setting, as it depends on the different levels of transparency of a material, caused by variations in the material thickness, and the exact positioning of the polymerization device. These varying conditions can cause different zones within a resin composite cement, where the chemical and dual curing reactions take place simultaneously. While this could reduce the conversion rate, it might also reduce shrinkage [41]. As curing parameters might hold a strong influence on crack propagation, future studies should focus on investigating this aspect further by varying the duration to light exposure, light intensity, and the wavelengths of the employed polymerization devices. The determination and analyzation of the degree of conversion could in this context enhance our understanding of the observed polymerization stress results further [8]. One further limitation of the present study is constituted by the layer thickness of the fixing material, with an optimal cement gap in the clinical setting varying between 30 and $50 \mu \mathrm{m}$. As a reduced thickness of the fixing

Table 3 Descriptive statistics for the crack lengths $[\mu \mathrm{m}]$ in the ceramic

\begin{tabular}{|c|c|c|c|c|c|c|}
\hline \multirow[t]{2}{*}{ Cement } & \multicolumn{2}{|c|}{ Crack length (initial) } & \multicolumn{2}{|c|}{ Crack length (after polymerization) } & \multicolumn{2}{|c|}{ Crack length $(\Delta)$} \\
\hline & Mean $\pm \mathrm{SD}$ & $95 \% \mathrm{CI}$ & Mean \pm SD & $95 \% \mathrm{CI}$ & Mean \pm SD & $95 \% \mathrm{CI}$ \\
\hline G-CEM & $212 \pm 13$ & {$[204 ; 220]$} & $224 \pm 11$ & {$[217 ; 230]$} & $12.2 \pm 9.1^{\mathrm{ab}}$ & {$[17.5 ; 6.7]$} \\
\hline iCEM & $210 \pm 13$ & {$[202 ; 218]$} & $220 \pm 17$ & {$[210 ; 230]$} & $9.9 \pm 5.5^{\mathrm{ab}}$ & {$[13.1 ; 6.6]$} \\
\hline Bifix SE & $209 \pm 10$ & {$[203 ; 215]$} & $224 \pm 13$ & {$[217 ; 232]$} & $15.0 \pm 7.2^{\mathrm{ab}}$ & {$[19.2 ; 10.7]$} \\
\hline Maxcem Elite & $213 \pm 19$ & {$[202 ; 224]$} & $228 \pm 13$ & {$[220 ; 236]$} & $14.7 \pm 11.0^{\mathrm{ab}}$ & {$[21.2 ; 8.1]$} \\
\hline PANAVIA SA & $215 \pm 18$ & {$[205 ; 226]$} & $227 \pm 14$ & {$[218 ; 236]$} & $11.4 \pm 7.6^{* \mathrm{ab}}$ & {$[15.9 ; 6.8]$} \\
\hline SoloCem & $222 \pm 9$ & {$[217 ; 227]$} & $230 \pm 11$ & {$[223 ; 237]$} & $8.0 \pm 5.7^{\mathrm{ab}}$ & {$[11.3 ; 4.6]$} \\
\hline SmartCem 2 & $216 \pm 11$ & {$[209 ; 223]$} & $232 \pm 25$ & {$[217 ; 247]$} & $15.8 \pm 18.4^{* a b}$ & {$[26.8 ; 4.8]$} \\
\hline SpeedCEM & $219 \pm 16$ & {$[209 ; 228]$} & $233 \pm 15$ & {$[224 ; 242]$} & $14.2 \pm 7.7^{\mathrm{ab}}$ & {$[18.7 ; 9.6]$} \\
\hline RelyX Unicem 2 & $218 \pm 9$ & {$[212 ; 223]$} & $237 \pm 10$ & {$[231 ; 242]$} & $18.9 \pm 7.3^{\mathrm{b}}$ & {$[23.2 ; 14.6]$} \\
\hline Ketac Cem (control group) & $223 \pm 11$ & {$[216 ; 229]$} & $224 \pm 12$ & {$[217 ; 231]$} & $1.0 \pm 5.2^{* \mathrm{a}}$ & {$[4.0 ; 2.2]$} \\
\hline
\end{tabular}

*Not normally distributed

${ }^{\mathrm{ab}}$ Different letters present significant differences between the different cements 
Table 4 Descriptive statistics for the polymerization stress [MPa] of the different cements

\begin{tabular}{|c|c|c|}
\hline \multirow[t]{2}{*}{ Cement } & \multicolumn{2}{|c|}{ Polymerization stress [MPa] } \\
\hline & Mean \pm SD & $95 \% \mathrm{CI}$ \\
\hline G-CEM & $3.34 \pm 2.44^{\mathrm{abc}}$ & {$[1.86 ; 4.82]$} \\
\hline iCEM & $2.87 \pm 1.37^{\mathrm{ab}}$ & {$[2.00 ; 3.80]$} \\
\hline Bifix SE & $4.17 \pm 1.86^{\mathrm{bc}}$ & {$[3.00 ; 5.30]$} \\
\hline Maxcem Elite & $4.47 \pm 2.49^{\mathrm{bc}}$ & {$[2.96 ; 6.00]$} \\
\hline PANAVIA SA & $3.09 \pm 2.05^{* a b c}$ & {$[1.85 ; 4.34]$} \\
\hline SoloCem & $2.15 \pm 1.41^{\mathrm{ab}}$ & {$[1.29 ; 3.00]$} \\
\hline SmartCem 2 & $5.90 \pm 1.22^{\mathrm{c}}$ & {$[5.15 ; 6.64]$} \\
\hline SpeedCEM & $3.99 \pm 2.12^{\mathrm{bc}}$ & {$[2.70 ; 5.27]$} \\
\hline RelyX Unicem 2 & $4.74 \pm 1.67^{\mathrm{bc}}$ & {$[3.72 ; 5.75]$} \\
\hline Ketac Cem (control group) & $0.39 \pm 0.29^{* a}$ & {$[0.22 ; 0.57]$} \\
\hline
\end{tabular}

*Not normally distributed

${ }^{\mathrm{ab}}$ Different letters present significant differences between the different cements

material should in theory reduce shrinkage, the present results need to be confirmed in future investigations expanding this novel measurement approach to imitate clinical situations as closely as possible. The configuration factor, referring to the number of bonded to un-bonded surfaces of a cavity, should also be taken into account in future study designs. While this study only examined a limited number of products, in regard to both the resin composite cements and the feldspar ceramic, future examinations should focus on testing a wider range of materials, paying special attention to their respective compositions and ensuing material properties. The choice of resin composite cement is, of course, only one factor among many that should be considered in the workflow of fixing a dental restoration, where optimal conditions allow for an enhanced treatment quality. Under laboratory conditions, crack initiation and propagation are furthermore influenced by the strength and load duration of the Vickers indentations and the distance of the indentations to the edge of the hole. Further studies are warranted to verify, whether the results obtained using this new methodology for determining the polymerization stress of self-adhesive resin composite cements can be transferred to the clinical practice.

\section{Conclusions}

Self-adhesive resin composite cements differ in their development of polymerization stress, which may affect the durability of the restorations. For restorations made from ceramics with lower flexural strength, such as feldspar ceramics, resin composite cement materials with less polymerization stress should be preferred.
Acknowledgments The authors would like to thank the manufacturer 3M, Coltene/Whaledent, Dentsply Sirona, GC Europe, Kerr, Ivoclar Vivadent, and VOCO for providing the cement materials.

Funding information Open Access funding provided by Projekt DEAL.

\section{Compliance with ethical standards}

Conflict of interest The authors declare that they have no conflict of interest.

Ethical approval This article does not contain any studies with human participants or animals performed by any of the authors.

Informed consent For this type of study, formal consent was not required.

Open Access This article is licensed under a Creative Commons Attribution 4.0 International License, which permits use, sharing, adaptation, distribution and reproduction in any medium or format, as long as you give appropriate credit to the original author(s) and the source, provide a link to the Creative Commons licence, and indicate if changes were made. The images or other third party material in this article are included in the article's Creative Commons licence, unless indicated otherwise in a credit line to the material. If material is not included in the article's Creative Commons licence and your intended use is not permitted by statutory regulation or exceeds the permitted use, you will need to obtain permission directly from the copyright holder. To view a copy of this licence, visit http://creativecommons.org/licenses/by/4.0/.

\section{References}

1. Edelhoff D, Ozcan M (2007) To what extent does the longevity of fixed dental prostheses depend on the function of the cement? Working group 4 materials: cementation. Clin Oral Implants Res 18(Suppl 3):193-204. https://doi.org/10.1111/j.1600-0501.2007. 01442.x

2. Abad-Coronel C, Naranjo B, Valdiviezo P (2019) Adhesive systems used in indirect restorations cementation: review of the literature. Dent J (Basel):7. https://doi.org/10.3390/dj7030071

3. Pameijer CH (2012) A review of luting agents. Int J Dent 2012: 752861-752867. https://doi.org/10.1155/2012/752861

4. Ferracane JL, Stansbury JW, Burke FJ (2011) Self-adhesive resin cements - chemistry, properties and clinical considerations. J Oral Rehabil 38:295-314. https://doi.org/10.1111/j.1365-2842.2010. 02148.x

5. Makkar S, Malhotra N (2013) Self-adhesive resin cements: a new perspective in luting technology. Dent Update 40:758-760, 763-4, 767-8. https://doi.org/10.12968/denu.2013.40.9.758

6. Frassetto A, Navarra CO, Marchesi G, Turco G, Di Lenarda R, Breschi L, Ferracane JL, Cadenaro M (2012) Kinetics of polymerization and contraction stress development in self-adhesive resin cements. Dent Mater 28:1032-1039. https://doi.org/10.1016/j. dental.2012.06.003

7. Kitzmuller K, Graf A, Watts D, Schedle A (2011) Setting kinetics and shrinkage of self-adhesive resin cements depend on cure-mode and temperature. Dent Mater 27:544-551. https://doi.org/10.1016/j. dental.2011.02.004

8. Spinell T, Schedle A, Watts DC (2009) Polymerization shrinkage kinetics of dimethacrylate resin-cements. Dent Mater 25:1058 1066. https://doi.org/10.1016/j.dental.2009.04.008 
9. Ferracane JL (2005) Developing a more complete understanding of stresses produced in dental composites during polymerization. Dent Mater 21:36-42. https://doi.org/10.1016/j.dental.2004.10.004

10. Mantri SP, Mantri SS (2013) Management of shrinkage stresses in direct restorative light-cured composites: a review. J Esthet Restor Dent 25:305-313. https://doi.org/10.1111/jerd.12047

11. Peutzfeldt A, Asmussen E (2004) Determinants of in vitro gap formation of resin composites. J Dent 32:109-115. https://doi.org/ 10.1016/j.jdent.2003.08.008

12. Davidson CL, de Gee AJ (1984) Relaxation of polymerization contraction stresses by flow in dental composites. J Dent Res 63:146148. https://doi.org/10.1177/00220345840630021001

13. Irie M, Tanaka J, Maruo Y, Nishigawa G (2014) Vertical and horizontal polymerization shrinkage in composite restorations. Dent Mater 30:e189-e198. https://doi.org/10.1016/j.dental.2014.02.018

14. Tantbirojn D, Versluis A, Pintado MR, DeLong R, Douglas WH (2004) Tooth deformation patterns in molars after composite restoration. Dent Mater 20:535-542. https://doi.org/10.1016/j.dental. 2003.05.008

15. Yamamoto T, Ferracane JL, Sakaguchi RL, Swain MV (2009) Calculation of contraction stresses in dental composites by analysis of crack propagation in the matrix surrounding a cavity. Dent Mater 25:543-550. https://doi.org/10.1016/j.dental.2008.10.008

16. Baroudi K, Saleh AM, Silikas N, Watts DC (2007) Shrinkage behaviour of flowable resin-composites related to conversion and filler-fraction. J Dent 35:651-655. https://doi.org/10.1016/j.jdent. 2007.05.001

17. Goncalves F, Kawano Y, Braga RR (2010) Contraction stress related to composite inorganic content. Dent Mater 26:704-709. https://doi.org/10.1016/j.dental.2010.03.015

18. Kramer N, Reinelt C, Richter G, Petschelt A, Frankenberger R (2009) Nanohybrid vs. fine hybrid composite in class II cavities: clinical results and margin analysis after four years. Dent Mater 25: 750-759. https://doi.org/10.1016/j.dental.2008.12.003

19. Meredith N, Setchell DJ (1997) In vitro measurement of cuspal strain and displacement in composite restored teeth. J Dent 25: 331-337. https://doi.org/10.1016/s0300-5712(96)00047-4

20. Calheiros FC, Sadek FT, Braga RR, Cardoso PE (2004) Polymerization contraction stress of low-shrinkage composites and its correlation with microleakage in class $\mathrm{V}$ restorations. J Dent 32:407-412. https://doi.org/10.1016/j.jdent.2004.01.014

21. Davidson CL, de Gee AJ, Feilzer A (1984) The competition between the composite-dentin bond strength and the polymerization contraction stress. J Dent Res 63:1396-1399. https://doi.org/10. $1177 / 00220345840630121101$

22. de Gee AJ, Davidson CL, Smith A (1981) A modified dilatometer for continuous recording of volumetric polymerization shrinkage of composite restorative materials. J Dent 9:36-42. https://doi.org/10. 1016/0300-5712(81)90033-6

23. Watts DC, Cash AJ (1991) Determination of polymerization shrinkage kinetics in visible-light-cured materials: methods development. Dent Mater 7:281-287. https://doi.org/10.1016/S01095641(05)80030-2

24. Sun J, Lin-Gibson S (2008) X-ray microcomputed tomography for measuring polymerization shrinkage of polymeric dental composites. Dent Mater 24:228-234. https://doi.org/10.1016/j.dental.2007. 05.001

25. Kirsten M, Matta RE, Belli R, Lohbauer U, Wichmann M, Petschelt A, Zorzin J (2018) Hygroscopic expansion of self-adhesive resin cements and the integrity of all-ceramic crowns. Dent Mater 34: 1102-1111. https://doi.org/10.1016/j.dental.2018.04.008

26. Sokolowski G, Szczesio A, Bociong K, Kaluzinska K, Lapinska B, Sokolowski J, Domarecka M, Lukomska-Szymanska M (2018) Dental resin cements-the influence of water sorption on contraction stress changes and hydroscopic expansion. Materials (Basel) 11. https://doi.org/10.3390/ma11060973

27. Hattar S, Hatamleh M, Khraisat A, Al-Rabab'ah M (2014) Shear bond strength of self-adhesive resin cements to base metal alloy. J Prosthet Dent 111:411-415. https://doi.org/10.1016/j.prosdent. 2013.06.022

28. Lee S-EB J-H, Choi J-W, Jeon Y-C, Jeong C-M, Yoon M-J, Huh JB (2015) Comparative shear-bond strength of six dental selfadhesive resin cements to zirconia. Materials 8(6):3306-3315

29. Flury S, Lussi A, Peutzfeldt A, Zimmerli B (2010) Push-out bond strength of CAD/CAM-ceramic luted to dentin with self-adhesive resin cements. Dent Mater 26:855-863. https://doi.org/10.1016/j. dental.2010.05.001

30. Aschenbrenner CM, Lang R, Handel G, Behr M (2012) Analysis of marginal adaptation and sealing to enamel and dentin of four selfadhesive resin cements. Clin Oral Investig 16:191-200. https://doi. org/10.1007/s00784-010-0501-z

31. Dukic W (2019) Radiopacity of composite luting cements using a digital technique. J Prosthodont 28:e450-e459. https://doi.org/10. 1111/jopr.12578

32. Liebermann A, Roos M, Stawarczyk B (2017) The effect of different storage media on color stability of self-adhesive composite resin cements for up to one year. Materials (Basel) 10. https://doi.org/10. 3390/ma10030300

33. Faria-e-Silva A, Boaro L, Braga R, Piva E, Arias V, Martins L (2011) Effect of immediate or delayed light activation on curing kinetics and shrinkage stress of dual-cure resin cements. Oper Dent 36:196-204. https://doi.org/10.2341/10-153-L

34. Ehlers V, Kampf G, Stender E, Willershausen B, Ernst CP (2015) Effect of thermocycling with or without 1 year of water storage on retentive strengths of luting cements for zirconia crowns. J Prosthet Dent 113:609-615. https://doi.org/10.1016/j.prosdent.2014.12.001

35. Luthy H, Loeffel O, Hammerle CH (2006) Effect of thermocycling on bond strength of luting cements to zirconia ceramic. Dent Mater 22:195-200. https://doi.org/10.1016/j.dental.2005.04.016

36. Abo-Hamar SE, Hiller KA, Jung H, Federlin M, Friedl KH, Schmalz G (2005) Bond strength of a new universal self-adhesive resin luting cement to dentin and enamel. Clin Oral Investig 9:161167. https://doi.org/10.1007/s00784-005-0308-5

37. Kim MJ, Kim YK, Kim KH, Kwon TY (2011) Shear bond strengths of various luting cements to zirconia ceramic: surface chemical aspects. J Dent 39:795-803. https://doi.org/10.1016/j. jdent.2011.08.012

38. Selz CF, Strub JR, Vach K, Guess PC (2014) Long-term performance of posterior InCeram Alumina crowns cemented with different luting agents: a prospective, randomized clinical split-mouth study over 5 years. Clin Oral Investig 18:1695-1703. https://doi. org/10.1007/s00784-013-1137-6

39. Luhrs AK, Guhr S, Gunay H, Geurtsen W (2010) Shear bond strength of self-adhesive resins compared to resin cements with etch and rinse adhesives to enamel and dentin in vitro. Clin Oral Investig 14:193-199. https://doi.org/10.1007/s00784-009-0279-z

40. Stawarczyk B, Beuer F, Ender A, Roos M, Edelhoff D, Wimmer T (2013) Influence of cementation and cement type on the fracture load testing methodology of anterior crowns made of different materials. Dent Mater J 32:888-895. https://doi.org/10.4012/dmj. 2013-147

41. Arrais CAG, Giannini M, Rueggeberg FA, Pashley DH (2007) Effect of curing mode on microtensile bond strength to dentin of two dual-cured adhesive systems in combination with resin luting cements for indirect restorations. Oper Dent 32:37-44

Publisher's note Springer Nature remains neutral with regard to jurisdictional claims in published maps and institutional affiliations. 